\title{
UM JOGO DIDÁTICO PARA O ENSINO DE EQUILÍBRIO QUÍMICO
}

\author{
A DIDACTIC GAME FOR THE TEACHING OF CHEMICAL EQUILIBRIUM
}

\author{
Rafael Soares Silva \\ Universidade Cruzeiro do Sul, São Paulo, Brasil. E-mail: doc.rafaelsoares@gmail.com \\ https://orcid.org/0000-0001-9994-6653
}

DOI: https://doi.org/10.46550/amormundi.v2i1.30

Recebido em: 17.10.2020

Aceito em: 03.01.2021

\begin{abstract}
Resumo: Este trabalho trata da execução de uma proposta de um jogo didático para facilitar o entendimento do conceito de equilíbrio químico. Atualmente, a abordagem lúdica no ensino de química por meio de jogos educacionais vem sendo muito utilizada como ferramenta pedagógica no processo de ensino aprendizagem. Esta pesquisa possui uma abordagem metodológica qualitativa (Lüdcke \& Andre,1986), amparada pela proposta de experimentação de Giordan (1999), que evidenciou que a experimentação é uma das metodologias alternativas na busca pela contextualização do conteúdo. A atividade experimental foi realizada com alunos do $2^{\circ}$ ano do Ensino Médio de uma escola pública do Estado de Sáo Paulo. Os resultados apontaram que a execução do jogo auxiliou no ensino e aprendizagem dos conceitos de equilíbrio químico. Durante a execução do jogo os alunos mostraram-se motivados, estimulando o caráter investigativo, a tomada de decisão e a aprendizagem colaborativa.
\end{abstract}

Palavras-chave: Ensino de Química. Jogo educativo. Equilíbrio Químico.

Abstract: This work deals with the execution of a didactic game proposal to facilitate the understanding of the concept of chemical equilibrium. Currently, the playful approach to teaching chemistry through educational games has been widely used as a pedagogical tool in the teaching-learning process. This research has a qualitative methodological approach (Lüdcke \& Andre, 1986), supported by Giordan's (1999) experimentation proposal, which showed that experimentation is one of the alternative methodologies in the search for contextualization of the content. The experimental activity was carried out with students from the 2nd year of high school at a public school in the state of Säo Paulo. The results showed that a game execution helped in the teaching and learning of chemical equilibrium concepts. During the execution of the game the students defined themselves motivated, stimulating the investigative character, the decision making and the collaborative learning.

Keywords: Chemistry teaching. Educational Game. Chemical balance

1 Introdução

o ensino de Química a utilização de jogos didáticos apresenta-se como uma
ferramenta importante a ser utilizada durante as aulas. Podendo contribuir, especialmente com a memorização de nomenclaturas além de melhorar a interação entre alunos 
e as relaçóes entre alunos e professores. Podemos ressaltar ainda que, o professor pode adaptar os jogos de acordo com os conteúdos a serem abordados e com a realidade em que está inserido no ambiente escolar (SILVA; AMARAL, 2020).

$\mathrm{O}$ uso dos jogos tem sido empregado contrapondo às críticas ao ensino tradicional onde muitas vezes os alunos são tratados como meros ouvintes das informaçôes que o professor expõe. Tais informações, quase sempre, não se relacionam aos conhecimentos prévios que os estudantes construíram ao longo de sua vida. E quando não há relação entre o que o aluno já sabe e aquilo que ele está aprendendo, a aprendizagem não é significativa (GUIMARÃES, 2009).

Soares; Okumura; Cavalheiro (2013), reforçam que o uso de jogos didáticos no ensino de Química tem despertado o interesse nos alunos. Tal interesse advém da diversão proporcionada pelos jogos e tem efeito positivo no aspecto disciplinar (SOARES; OKUMURA; CAVALHEIRO, 2013).

Silva e Amaral (2020) destacam o grande diferencias dos jogos:

Esse tipo de atividade apresenta um diferencial, frente a outras já conhecidas e difundidas no âmbito da comunidade de profissionais, voltados ao Ensino de Química no Brasil, pois os jogos são elementos muito valiosos no processo de apropriação do conhecimento, permitindo o desenvolvimento de competências no âmbito da comunicação, das relaçóes interpessoais, da liderança e do trabalho em equipe e utilizando a relação cooperação/competição em um contexto formativo, pois o aluno coopera com os colegas de equipe e compete com as outras equipes que são formadas pelos demais colegas da turma (SILVA; AMARAL, 2020, p. 226).

Nesse sentido, o uso de recursos didáticos de fácil acesso e com produção de baixo custo, como jogos e alguns experimentos, têm proporcionado diferentes benefícios a formação cidadã dos estudantes como aulas dinâmicas, aumento na participação, motivação e interesse pelos conteúdos e seus conceitos e ainda melhorias na relação entre aluno e professor, favorecendo a aprendizagem, de forma descontraída e divertida, tornando as aulas mais prazerosas (SALES et. al., 2018).

Kishimoto (1994), aponta que o jogo é considerado um tipo de atividade lúdica, e que possui duas funçóes: a lúdica e a educativa. Elas devem estar em equilíbrio, pois se a função lúdica prevalecer, não passará de um jogo e se a função educativa for predominante será apenas um material didático. Os jogos são indicados como um tipo de recurso didático educativo que podem ser utilizados em momentos distintos, como na apresentaçáo de um conteúdo, ilustraçáo de aspectos relevantes ao conteúdo, como revisão ou síntese de conceitos importantes e avaliação de conteúdos já desenvolvidos (CUNHA; 2004).

A presente pesquisa utilizou o jogo como forma de abordar o tema de Equilíbrio Química para alunos do $2^{\circ}$ ano do Ensino Médio de uma escola pública estadual de São Paulo. A proposta da aula experimental com um jogo didático para o Ensino de Equilíbrio Químico compreende a aplicação de uma proposta feita no livro de Química Ciscato et. al. (2016), como objetivo de provocar nos alunos um caráter investigativo sobre a aprendizagem dos conceitos de equilíbrio químico.

Nesse sentido, Sales et. al., (2018) apontam que o uso de recursos didáticos como jogos e alguns experimentos, têm proporcionado diferentes benefícios à formação cidadã dos estudantes a partir de aulas dinâmicas que contribuem para o aumento na participação, motivação e interesse 
pelos conteúdos e seus conceitos e ainda melhorias na relação entre aluno e professor, favorecendo a aprendizagem, de forma descontraída e divertida, tornando as aulas mais prazerosas.

\subsection{Oensino de equilíbrio químico}

Equilíbrio Químico é a parte da Físico-Química que estuda as reações reversíveis (aquelas que podem retomar suas características anteriores, acontecendo também em direçôes opostas) assim como as condiçóes para o estabelecimento deste Equilíbrio. Quando falamos que um sistema químico está em Equilíbrio, significa dizer que há neste um estado dinâmico, onde vários processos estão ocorrendo ao mesmo tempo e à mesma velocidade (SALES et. al 2018).

Hackerman (1946) alerta para o fato de que uma das dificuldades relacionadas ao ensino de equilíbrio químico é que ele é visto, muitas vezes, como tendo dois compartimentos, num dos quais encontra-se o reagente e no outro o produto. Tal constatação também é detectada por Machado e Aragão (1996), sendo que esse aspecto será discutido posteriormente. (SOARES; OKUMURA; CAVALHEIRO, 2013)

O conteúdo acima citado compóe o currículo do segundo ano do ensino médio e geralmente é apontado por professores de Química como um dos mais difíceis de ser trabalhado. Para os estudantes existem dificuldades na compreensão dos conceitos que envolvem tal conteúdo, isso porque na maioria das vezes ele é desenvolvido de forma descontextualizada, sem a proposta de metodologias dinâmicas que facilitem o processo de ensino aprendizagem, gerando dificuldades de compreensão, assimilação e aplicação dos conceitos (SALES et. al 2018).

Além disso, o tema equilíbrio químico foi escolhido porque não só os alunos encontram dificuldade de assimilação desse tópico, mas também os professores têm dificuldades em ensinálo, dado que ele envolve um conjunto complexo de relações entre quantidades de espécies químicas presentes (Pereira, 1989).Nesse sentido, esta pesquisa busca investigar as contribuiçóes de um jogo didático reproduzido e aplicado conforme orientaçóes de (SOARES; OKUMURA; CAVALHEIRO, 2013) durante uma aula de Química do ensino médio para o ensino do conteúdo de Equilíbrio Químico.

Dentro dessa linha, considera-se o desenvolvimento de atividades lúdicas envolvendo materiais concretos e manipuláveis para associação com conceitos abstratos do conteúdo de Química (OKUMURA et al., 2000 e 2001).

\section{Metodologia}

Esta pesquisa possui uma abordagem metodológica qualitativa (LÜDCKE \& ANDRE, 1986), possuindo um ambiente natural como fonte direta de dados e o pesquisador como seu principal instrumento, sendo a preocupação maior com o processo do que com o produto final. Denzin \& Lincoln(2006), reforça, que a pesquisa qualitativa é um campo de investigação que permite a interligação de termos, conceitos e suposiçóes.

Para Giordan (1999) a experimentação desperta um forte interesse entre os alunos, que atribuem a esta um caráter motivador, lúdico e essencialmente vinculado aos sentidos. Este autor também destacou a contribuição das aulas práticas para a aprendizagem colaborativa, através da realização de experimentos em equipe e a colaboração entre as equipes. 
Gonçalves et. al., (2020) reforçam o uso da experimentação como metodologia uma vez que ela pode tornar o aluno mais ativo, aquele que faz observaçōes, formula hipóteses, questiona, ou seja, para deixar de ser apenas um receptor do conhecimento. A fim de que isso aconteça, a atividade experimental nas aulas de Química pode ser bem estruturada sem deixar assim, que se torne uma prática de laboratório em que os alunos apenas fazem o que é descrito em um roteiro rígido, mas com espaço para argumentação.

Este trabalho trata da apresentação de um conceito por meio de um modelo macroscópico que, associado a uma analogia, tem o propósito de ajudar os alunos a entenderem o modelo teórico vigente (microscópico) (SOARES; OKUMURA; CAVALHEIRO, 2013).

$\mathrm{Na}$ tentativa de abordar esses aspectos, o objetivo deste trabalho é facilitar o entendimento do conceito de equilíbrio químico, com uma atividade lúdica que pode ser realizada na própria sala de aula. Os experimentos laboratoriais corriqueiramente propostos nem sempre ilustram todas as características do equilíbrio químico ou envolvem o uso de reagentes de custo elevado e de difícil aquisição (SOARES; OKUMURA; CAVALHEIRO, 2013)

\subsection{Materiais}

- 20 bolas de plástico de mesmo tamanho

- 1 caixa de papeláo (preferencialmente de sapato)

- Papel sulfite

- Caneta

- Cronômetro

\subsection{Procedimentos}

No centro da caixa, deve-se pintar o sinal da dupla seta de equilíbrio e as letras A e B, conforme mostra a Figura 1.

Figura 1: Caixa com dupla seta e as letras A e B.

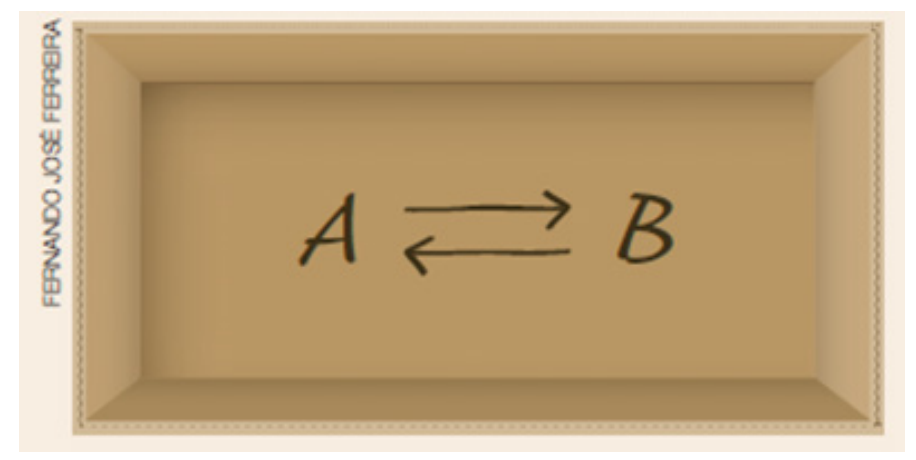

Fonte: Ciscato et. al., (2016, p.338)

De um lado da caixa, deve-se posicionar o conjunto A ("reagente"); do outro, o conjunto B("produto") como pode ser observado na figura 2. Inicialmente, prepara-se o conjunto A com 20 unidades de bolinhas. O conjunto B fica vazio. O jogo se inicia com um apito. O segundo apito, 5 segundos depois, indica o transporte da primeira unidade de A para B. A cada apito 
(sugere-se o intervalo fixo de 5 segundos), a transferência se repete.

Depois de algum tempo (por exemplo, 60 segundos), o professor emite um apito duplo. A partir de então, a cada apito deve-se continuar transferindo uma unidade de A para B, mas simultaneamente se deve transferir outra unidade de B para A. Sugere-se um total de 24 transferências.

Figura 2: Alunas organizando o jogo para início da execução de propostas.

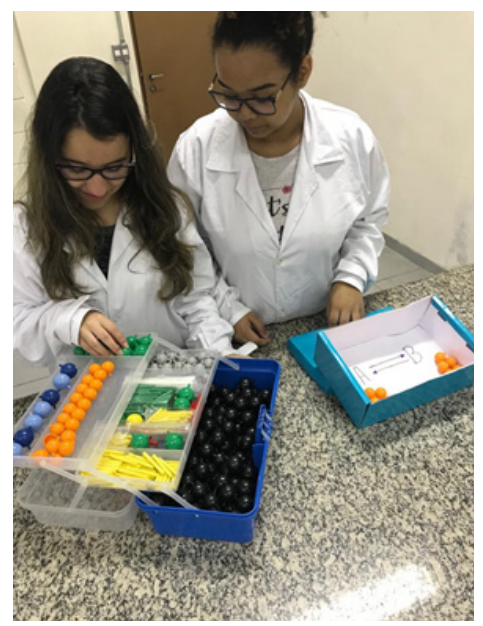

Fonte: Dados da pesquisa

\section{Resultados e discussáo}

Os estudantes participantes da pesquisa são alunos do segundo ano do ensino médio. Ao todo participaram da pesquisa 13 alunos. Esse jogo didático foi produzido com materiais de fácil aquisição e visa enriquecer o entendimento do conceito de equilíbrio químico. As bolinhas podem ser de isopor, por ser mais acessível. Observe a representação da figura 3, onde pode-se observar a transferência das substâncias.

Figura 3: Transferência após 5 segundos.

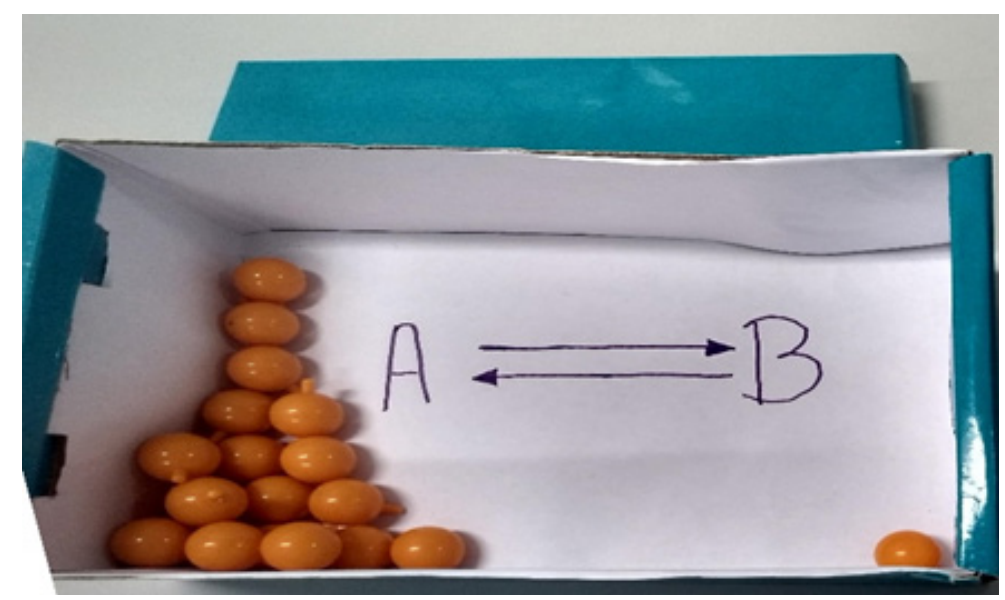

Fonte: Dados da pesquisa

Após 60 segundos, continuou-se transferindo um elemento de A para B, mas simultaneamente transfere-se um elemento de B para A, a cada 5 segundos efetua-se 17 transferências no total de 85 segundos. Durante todo o processo, um dos alunos ficou responsável 
por controlar o tempo e um outro aluno por fazer a transferência e anotar os dados/resultados.

Obtidos esses resultados, pode-se fazer a transposição conceitual associando-se a transferência de bolas com os conceitos de reação química e os elementos presentes nos conjuntos A e B com reagentes e produtos, dessa reação e sua quantidade com a concentração.

O jogo foi realizado no laboratório de química, e o resultado da atividade foi a construção da tabela 1 que reúne o número de unidades em cada conjunto, $\mathrm{A}$ e $\mathrm{B}$, em função do tempo O objetivo do processo é obter uma tabela de número de elementos nos conjuntos A(NA) e $\mathrm{B}(\mathrm{NB})$, em função do tempo. Deve-se calcular a reação NB/NA em função do tempo designado anteriormente na metodologia.

A tabela a seguir mostra os dados obtidos em cada transferência e tempo decorrido, onde o N(A) é o produto e o $\mathrm{N}(\mathrm{B})$ é o reagente.

Tabela 1: Resultados obtidos através da experiência realizada, para $K=1,5$.

\begin{tabular}{|c|c|c|c|c|}
\hline TRANSFERÊNCIA & $\begin{array}{c}\text { TEMPO } \\
\text { DECORRIDO } \\
(s)\end{array}$ & $\mathbf{N}(A)$ & $\mathbf{N}(\mathrm{B})$ & $\mathbf{N B} / \mathbf{N A}^{1}$ \\
\hline 0 & 0 & 20 & 0 & $\ldots$ \\
\hline 1 & 5 & 19 & 1 & 0,053 \\
\hline 2 & 10 & 18 & 2 & 0,111 \\
\hline 3 & 15 & 17 & 3 & 0,009 \\
\hline 4 & 20 & 16 & 4 & 0,25 \\
\hline 5 & 25 & 15 & 5 & 0,333 \\
\hline 6 & 30 & 14 & 6 & 0,429 \\
\hline 7 & 35 & 13 & 7 & 0,538 \\
\hline 8 & 40 & 12 & 8 & 0,667 \\
\hline 9 & 45 & 11 & 9 & 0,818 \\
\hline 10 & 50 & 10 & 10 & 1 \\
\hline 11 & 55 & 9 & 11 & 1,2 \\
\hline 12 & 60 & 8 & 12 & 1,5 \\
\hline 13 & 65 & 8 & 12 & 1,5 \\
\hline 14 & 70 & 8 & 12 & 1,5 \\
\hline 15 & 75 & 8 & 12 & 1,5 \\
\hline 16 & 80 & 8 & 12 & 1,5 \\
\hline 17 & 85 & 8 & 12 & 1,5 \\
\hline
\end{tabular}

Fonte: Dados da pesquisa

A tabela acima foi construída a partir dos resultados experimentais, o valor NB/NA varia com o tempo até tornar-se constante e cada valor pode ser relacionado ao quociente de reação em cada tempo. Já os valores constantes permitem uma relação com a constante de equilíbrio. Em cada uma das três situaçóes foi evidenciado a relação entre o valor numérico da constante de equilíbrio e a predominância de reagentes ou produtos em um sistema que atingiu o equilíbrio químico, desmistificando a ideia de que o equilíbrio é atingido quando a quantidade de reagente é igual à de produto. Aliás, por esse motivo, aconselha-se não fazer o experimento com apito

$1 \mathrm{O}$ valor NB/NA varia com o tempo até tornar-se constante e cada valor pode ser relacionado ao quociente de reação em cada tempo. Ciscato et. al (2006). 
duplo quando o quociente for igual a 1,0 como sugestão do roteiro de execução do jogo proposto no livro didático (CISCATO et. al 2006).

Associado à construção da tabela os alunos construíram um gráficos semelhantes àqueles utilizados nos estudos dos equilíbrios químicos, conforme pode ser observado na fugira 4 .

Figura 4: Gráfico dos resultados obtidos através da tabela

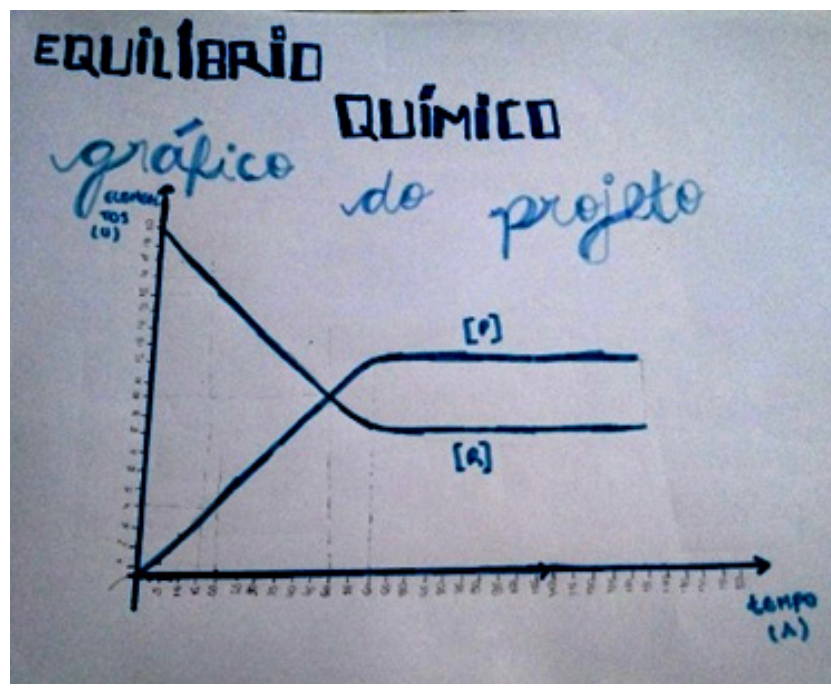

Fonte: Dados da pesquisa

Decorrem as seguintes características em relação ao experimento realizado sobre equilíbrio químico como foi proposto por Ciscato et. al. (2016, p.338), o equilíbrio químico é dinâmico (associaçáo com o movimento constante das bolas); Taxas de reação direta e inversa são iguais, mas somente depois de "atingido o equilíbrio" (a cada bola que vai de A para B, outra vem de $\mathrm{B}$ para $\mathrm{A}$ ); e as concentraçóes não se alteram depois de atingido o equilíbrio (o número de unidades em cada conjunto não se altera).

Dentro da atividade lúdica, foi possível encontrar os resultados com o tempo e a quantidade de elementos em cada lado (reagente e produto), chegando ao gráfico em que conforme o tempo passa o lado do produto ganha uma substância a cada 5 segundos, quando alcançado 60 segundos, há uma transferência mútua, chegando a uma constante de 1,5.

Inúmeros são os jogos ou atividades lúdicas que poderiam ser (re) criados ou adaptados em um contexto do ensino de Ciências - Química. Essas são apenas algumas de uma gama de possibilidades quase infinita. É sempre extremamente necessário, contudo, adequá-las ao contexto de ensino, à faixa etária dos aprendizes, aos objetivos, ao espaço físico etc. E cabe ao professor esse discernimento (SILVA; AMARAL, 2020).

Soares; Okumura; Cavalheiro (2013), aponta que o modelo proposto apresenta algumas limitaçôes e diferenças em relação ao sistema químico real. É função do professor estar atento a essas limitaçóes quando da transposiçáo conceitual e ao uso correto da analogia. Deve ficar claro tanto para alunos como para professores que se trata de um modelo explicativo, no qual caixas e bolas são parte de uma representação palpável e macroscópica de um conceito microscópico e abstrato.

Uma dessas limitações relaciona-se ao fato de que a reação química não ocorre em intervalos 
de tempo, como os que estão definidos neste trabalho; no caso presente, esses intervalos foram utilizados para organizar as transferências. Deve-se também observar que a reação reversa ocorre desde o início do processo, o que não é observado quando se manipula as bolas de uma caixa para outra. Uma outra limitação relaciona-se à forma da curva obtida, que apresenta um perfil linear com uma quebra quando o "equilíbrio" é atingido. (SOARES; OKUMURA; CAVALHEIRO, 2013)

\section{Consideraçóes finais}

A utilização dos jogos no processo educativo, mostrou-se como um instrumento facilitador da integração, da sociabilidade, do despertar lúdico, e principalmente do aprendizado. Durante a execuçấo do jogo pode-se perceber uma melhora significativa no entendimento dos conceitos de equilíbrio químico e constante de equilíbrio. Em concordância com o trabalho realizado por Soares et. al. (2013), a aplicação desse jogo despertou o interesse dos alunos pela aula, com consequências muito favoráveis no aspecto disciplinar. Acredita-se também que os benefícios obtidos com o uso desse jogo foi principalmente a visualizaçáo do Fenômeno de forma macroscópica.

\section{Referências}

CUNHA, Marcia Borin. Jogos de Química: Desenvolvendo habilidades e socializando o grupo. Encontro Nacional de Ensino de Química, v. 12, 2004.

GIORDAN, Marcelo. O papel da experimentação no ensino de ciências. Química nova na escola, v. 10, n. 10, p. 43-49, 1999.

GUIMARÃES, Cleidson Carneiro. Experimentação no ensino de química: caminhos e descaminhos rumo à aprendizagem significativa. Química nova na escola, v. 31, n. 3, p. 198202, 2009.

KISHIMOTO, Tizuko Morchida. O jogo e a educação infantil. Pro-posiçóes, v. 6, n. 2, p. 46-63, 1995.

HACKERMAN, Norman. The equilibrium concept in beginning college chemistry courses. Journal of Chemical Education, v. 23, n. 1, p. 45, 1946.

Silva, R. S.; Amaral, C. L. C. Jogos Pedagógicos no Ensino de Ciências: uma química perfeita. In: Schütz, J.A.; Mayer, L.(Org.). Vozes Contemporâneas da Educaçáo. 1ed.Cruz Alta (RS): Ilustração. 2020.

MACHADO, Andréa Horta; ARAGÃO, RMR de. Como os estudantes concebem o estado de equilíbrio químico. Química Nova na Escola, v. 4, n. 2, p. 18-20, 1996.

OKUMURA, F.; SOARES, M.H.F.B. e CAVALHEIRO, E.T.G. Simulação didática do equilíbrio químico. Livro de Resumos do II Encontro Latino Americano de Ensino de Química. Porto Alegre. 2000.

OKUMURA, F.; SOARES, M.H.F.B. e CAVALHEIRO, E.T.G. Simulação didática da lei de Lavoisier. Livro de Resumos da 24a Reuniáo Anual da SBQ. Poços de Caldas, Sociedade 
Brasileira de Química, 2001.

PEREIRA, M. P. A. Equilíbrio Químico-Dificuldades de aprendizagem I-Revisão de opiniōes não apoiadas por pesquisa. Revista Química Nova, v. 12, n. 1, p. 76-81, 1989.

SOARES, M. H. F. B.; OKUMURA, Fabiano; CAVALHEIRO, E. T. G. Proposta de um jogo didático para ensino do conceito de equilíbrio químico. Química nova na escola, v. 18, n. 1, p. 13-17, 2003.

SOARES, M. H. F. B. Jogos e atividades lúdicas para o ensino de química. Goiânia: Kelps, v. 196, 2013.

SALES, Maiane França et al. Um jogo didático para o ensino de química: uma proposta alternativa para o conteúdo de equílibrio químico. South American Journal of Basic Education, Technical and Technological, v. 5, n. 2, 2018. 